\title{
RNASET2 tag SNP but not CCR6 polymorphisms is associated with autoimmune thyroid diseases in the Chinese Han population
}

\author{
Xiao-jun Chen ${ }^{1}$, Xiao-hua Gong ${ }^{1}$, Ni Yan² ${ }^{2}$ Shuai Meng ${ }^{2}$, Qiu Qin², Yan-Fei Jiang ${ }^{2}$, Hai-Yan Zheng ${ }^{2}$ and Jin-an Zhang ${ }^{2 *}$
}

\begin{abstract}
Background: Polymorphisms of the CC chemokine receptor 6 (CCR6) and RNASET2 tag SNP have been shown to be associated with the susceptibility to several immune-related diseases. This study was conducted to identify the association of CCR6 and RNASET2 tag SNP with autoimmune thyroid diseases (AITDs) in the Chinese Han population.

Methods: We enrolled 1061 patients with AITDs, including 701 patients with Graves' disease (GD) and 360 patients with Hashimoto's thyroiditis (HT), and 938 healthy individuals for a case-control genetic association study. Three CCR6 single nucleotides polymorphisms (SNPs) (rs3093023/rs3093024/rs6902119) and one tagging SNP (rs9355610) within RNASET2 gene were selected for genotyping by multiplex polymerase chain reaction (PCR) and ligase detection reaction (LDR).

Results: The frequency of rs9355610 genotypes in the patients with GD differed significantly from that in the controls ( $p=0.017$ ). The frequency of the minor $\mathrm{G}$ allele of $\mathrm{rs} 9355610$ was significantly higher in the GD patients than in the healthy controls ( $p=0.005, \mathrm{OR}=1.225,95 \% \mathrm{Cl}: 1.063-1.412)$. However, we could not find significant differences in the genotype or allele frequencies of HT patients compared with healthy controls. After gender stratification, the frequency of the minor $\mathrm{G}$ allele in both male and female GD patients was significantly higher than that in the healthy controls $(p=0.036, O R=1.308,95 \% \mathrm{Cl}: 1.017-1.684 ; \mathrm{p}=0.048, \mathrm{OR}=1.19,95 \% \mathrm{Cl}: 1.001-1.413$; respectively);. Furthermore, the frequency of haplotype AT in GD patients was significantly lower than that in their control groups $(p=0.003)$ and showed a protective effect against GD (OR $=0.806,95 \% \mathrm{Cl}$ : 0.699-0.929). The frequency of haplotype GT in GD patients was significantly higher than that in their control groups $(p=0.048)$, indicating that GT was the risk haplotype to GD $(\mathrm{OR}=1.267,95 \% \mathrm{Cl}: 1.001-1.603)$. There were no significant differences in the allele or genotype frequencies of three SNPs of CCR6 (rs3093023/rs3093024/ rs69021 19) gene between GD patients, HT patients and controls.
\end{abstract}

Conclusions: Our results suggest that the rs9355610 tag SNP of RNASET2 gene is positively associated with susceptibility to GD in the Chinese Han population. No association was found for the tested CCR6 SNPs.

Keywords: RNASET2, CCR6, Single nucleotide polymorphisms (SNPs), Autoimmune thyroid diseases (AITDs), Graves' disease (GD), Hashimoto's thyroiditis (HT)

\section{Background}

Autoimmune thyroid disease (AITD) is an organ-specific autoimmune disease characterized by the break-down of self-tolerance to thyroid antigens and the occurrence in the serum of antibodies against thyroid self-antigens. Two typical AITDs, Graves' disease (GD) and Hashimoto's

\footnotetext{
* Correspondence: zhangjinan@hotmail.com

${ }^{2}$ Department of Endocrinology, Jinshan Hospital of Fudan University, No.1508 Longhang Road, Jinshan District, 201508 Shanghai, China

Full list of author information is available at the end of the article
}

thyroiditis (HT), affect up to $5 \%$ of the general population [1], and both of are characterized pathologically by infiltration of the thyroid by $\mathrm{T}$ and B-cells reactive to thyroid antigens, biochemically by the production of thyroid autoantibodies, and clinically by abnormal thyroid functions (hyperthyroidism in GD and hypothyroidism in HT) [2].

The current paradigm is that AITDs are complex diseases in which susceptibility genes and environmental triggers act in concert to initiate the autoimmune response to the thyroid. While the exact etiology of 
AITD is incompletely known, there is abundant evidence for a strong genetic influence on the development of AITD. The putative GD and HT susceptibility genes include both immune modifying genes HLA Class II gene $[3,4]$, cytotoxic $\mathrm{T}$ lymphocyte-associated factor 4 (CTLA-4) gene [5,6], CD40 gene [5-7], protein tyrosine phosphatase-22 (PTPN22) gene [5], and other thyroidspecific genes for the thyroid stimulating hormone receptor (TSHR) [5,8] and thyroglobulin (TG) [9], as well as the novel proinflammatory cytokine such as interleukin-17 (IL-17) [10] and IL-21 [11]. All these data suggest that genetic factors may play an important role in the pathogenesis of AITD.

CC chemokine receptor 6 (CCR6), a member of the $\beta$ chemokine receptor family, is expressed in immature dendritic cells, memory $\mathrm{T}$ cells, lymphocytes and B cells [12-14]. The CCR6 gene encodes C-C motif chemokine receptor 6 , the receptor for CCL20 and a surface marker for IL-17-producing T helper 17 (Th17) cells [13]. It is believed that CCL20/CCR6 signaling plays a role in the recruitment of not only immature dendritic cells and their precursors, but also Th17 cells, into sites of potential antigen entry [13]. The pathogenesis of various autoimmune diseases and inflammatory diseases has been linked to the involvement of Th17 cells, most of them reporting CCR6 as a key factor for involvement of Th17 cells [15-17]. We also have reported that IL-17 might play an key pole in the pathogenesis of HT and IL-17A/F polymorphisms may affect the susceptibility to AITD [10,18]. Recent studies have suggested that CCR6 polymorphisms are associated with an increased risk for a variety of autoimmune- or immune-mediated diseases, such as rheumatoid arthritis (RA) [19,20], Crohn's disease [21], systemic sclerosis (SSc) [22] and vitiligo [23]. However, it remains unknown whether CCR6 polymorphisms are associated with AITD in the Chinese population which was the subject of this study.

Chu et al. carried out a genome-wide association study (GWAS) of individuals with GD in a Chinese Han population and identified novel GD susceptibility loci rs9355610, within 6q27 chromosomal bands that contribute to generalized GD risk [24]. Of interest is the fact that HT is also the clinical subtype of AITDs and shares the similar genetic predisposition with GD. Whether genes in this region are also associated with HT is unknown and is therefore the subject of this study.

In this study, we therefore conducted a large casecontrol study to determine the genetic association of the selected SNP of CCR6(rs3093023/rs3093024/rs6902119) and one tagging SNP (rs9355610) within RNASET2 with AITD in a cohort of the Chinese Han population. Furthermore, we analyzed the association between genotypes and AITD clinical characteristics.

\section{Methods}

\section{Study population}

The study population $(\mathrm{n}=1999)$ consisted of 1061 Chinese Han non-related AITD patients including 701 patients with GD and 360 patients with HT; and 938 unrelated, ethnically matched healthy controls. All AITDs patients were enrolled from the Outpatient Department and Inpatient Department of Endocrinology of Jinshan Hospital of Fudan University; ethnically and geographically matched healthy controls were recruited from the Health Check-Up Center of the hospital. The subjects were all of self-reported Chinese Han ethnicity. This study was approved by the Ethics Committee of Jinshan Hospital of Fudan University. Written informed consent was obtained from all subjects. All procedures followed the tenets of the Declaration of Helsinki.

Inclusion criteria: AITDs patients were diagnosed as described in our published papers [25]. GD was diagnosed based on clinical and laboratory biochemical evidence of hyperthyroidism by the presence of diffuse goiter, and supported by the positive anti-thyroid stimulating hormone receptor antibody (TRAb) and/or anti-thyroid peroxidase antibody(TPO-Ab) and/or anti-thyroglobulin(Tg-Ab) and/ or exophthalmos. HT was diagnosed based on the presence of an enlarged thyroid and either TPO-Ab or Tg-Ab, with or without documented clinical and biochemical hypothyroidism. For the suspicious cases of HT, diagnoses were confirmed by fine needle aspiration biopsies (FNAB).

Exclusion criteria: All healthy subjects without clinical evidence (goiter, TPOAb, and TGAb) and family history of thyroid diseases and any other autoimmune diseases.

The clinical manifestations of AITD patients include: (1) adult- or childhood- onset AITDs, according to the age of disease onset ( $\leq 18$ years versus $\geq 19$ years); (2) presence or absence of ophthalmopathy in GD group (defined as a distinctive disorder characterized by inflammation and swelling of the extraocular muscles, eyelid retraction, periorbital edema, episcleral vascular injection, conjunctive swelling and proptosis); (3) presence or absence of thyroid dysfunction in HT group: euthyroid status or hypothyroidism; and (4) presence or absence of AITDs family history.

\section{DNA extraction and genotyping}

From all the study participants, peripheral venous blood of $2 \mathrm{~mL}$ was collected and genomic DNA was extracted from peripheral blood cells using the Nucleon Bacc kit (TianGen Biotech Co., Ltd., Beijing, China), according to the manufactures' guidelines. Four selected SNPs (rs3093023/rs3093024/rs6902119/rs9355610) were genotyped by ligase detection reactions (LDR) platform in Shanghai Biowing Applied Biotechnology Company (http://www.biowing.com.cn/). This is a well-established platform used by many researchers for studies including SNP genotyping [25]. The target DNA sequences were 
amplified using multiplex polymerase chain reaction (PCR) method with specific primer sequences as follows:

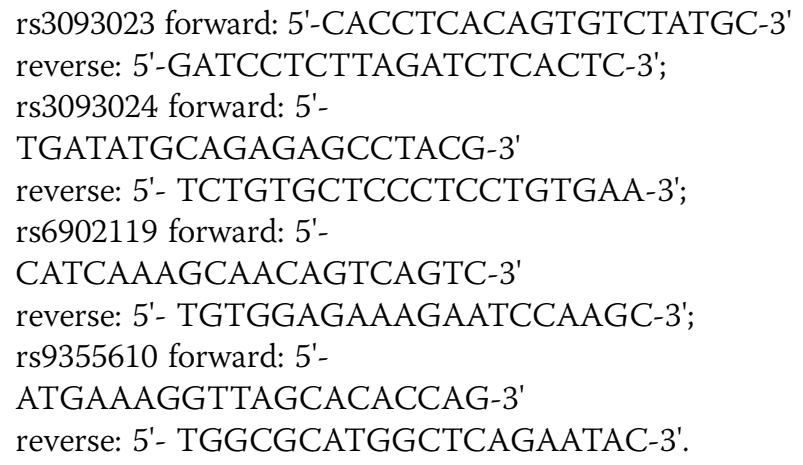

Extracted DNA was amplified by PCR using the GeneAmp PCR System 9600 (Perkin Elmer, Waltham, MA, USA) for PCR amplification. The reaction course included initial denaturation at $95^{\circ} \mathrm{C}$ for $2 \mathrm{~min}$, denaturation at $94^{\circ} \mathrm{C}$ for $30 \mathrm{~s}$, annealing at $56^{\circ} \mathrm{C}$ for $1 \mathrm{~min}$, extension at $65^{\circ} \mathrm{C}$ for $30 \mathrm{~s}$ with 35 cycles, and final extension at $65^{\circ} \mathrm{C}$ for $10 \mathrm{~min}$. After the reaction, $2 \mu \mathrm{L}$ of each product was run in a $3.0 \%$ agarose gel to determine whether the reaction had been successful. After the completion of the amplification, the ligation detection reaction for each subject was carried out in a final volume of $10 \mu \mathrm{l}$ containing $1 \mu \mathrm{L}$ buffer $(1 \times)$, $1 \mu \mathrm{L}$ Prob mix $(2 \mathrm{pmol} / \mu \mathrm{L}), 1 \mu \mathrm{L}$ of Multi-PCR product (100 ng/ $\mu \mathrm{L}$ ), $6.95 \mu \mathrm{L} \mathrm{H} \mathrm{H}_{2} \mathrm{O}, 0.05 \mu \mathrm{L}$ of $2 \mathrm{U} / \mu \mathrm{L}$ Taq DNA ligase (New England Biolabs, Ipswich, MA, USA). The LDR was performed using 40 cycles of denaturation at $95^{\circ} \mathrm{C}$ for $2 \mathrm{~min}$, annealing at $94^{\circ} \mathrm{C}$ for $15 \mathrm{~s}$ and extension at $50^{\circ} \mathrm{C}$ for $25 \mathrm{~s}$. The LDR fluorescent product was analyzed using an ABI sequencer 377 (Applied Biosystems), and the results were analyzed with Genemapper software.

In addition to ensuring quality of the assay, we made double positive controls (duplication of the same DNA samples) and negative controls (blank samples without DNA) in the processor of SNP genotyping. Quality control analysis was also performed so that only SNPs and samples which had passed the 95\% quality control threshold were subjected to further statistical analysis.

\section{Statistical analysis}

Statistical analyses were performed using SPSS version 17.0 software (SPSS Inc., Chicago, IL, USA). Each genetic marker was tested for Hardy-Weinberg equilibrium in the control population using the HWE program (http://ihg.gsf.de/cgi-bin/ hw/hwa1.pl). A linkage disequilibrium (LD) map used to define the haplotype blocks was constructed using Haploview software (version 4.2; http://www.broadinstitute.org/haplo view/haploview). The haplotype analysis was performed to compare distributions of haplotype frequencies of SNPs between cases and controls. All the allele and genotype frequencies between the patients and the controls were assessed by $x^{2}$-test. The two-tailed independent samples $t$ test was performed to evaluate the diversity of parameters between groups of different genotypes. To examine whether each SNP independently contributes to susceptibility to AITD, conditional logistic regression analysis was employed. All tests were two-tailed, considering p-values $<0.05$ as significant. Odds ratios were calculated for the minor allele at each SNP.

\section{Power calculation}

The power of the data was assessed using the Power and Sample Size Calculation software (Ps; version 3.0; http:// biostat.mc.vanderbilt.edu) [26]. Taking into account the expected frequency of the CCR6 rs9355610 minor allele (46.1\%) in the general population, the combined set of 1061 AITD cases and 938 controls provided a power of 81.7\% to detect an association between AITD and these variants, with an OR of 1.2 at the $5 \%$ significance level.

\section{Results}

\section{Clinical characteristics of the subjects}

To investigate whether four selected SNPs contribute to the susceptibility to AITD, we performed a case and control association study. As shown in Table 1, in the GD patients $69.5 \%$ were females, the mean age was 36.86 years; in the HT patients $87.8 \%$ were females, the mean age was 35.09 years. In the healthy controls, $67.1 \%$ individuals were females and the overall mean age was 38.61 years. There was no difference in age distribution between

Table 1 The demographic and clinical characteristics of the AITDs patients and the controls

\begin{tabular}{|c|c|c|c|}
\hline Characteristics & $\begin{array}{l}\text { GD patients } \\
(\mathrm{n}=701)\end{array}$ & $\begin{array}{l}\text { HT patients } \\
(n=360)\end{array}$ & $\begin{array}{l}\text { Controls } \\
(n=938)\end{array}$ \\
\hline \multicolumn{4}{|l|}{ Gender } \\
\hline Male (\%) & $214(30.5)$ & $44(12.2)$ & $309(32.9)$ \\
\hline Female (\%) & $487(69.5)$ & $316(87.8)$ & $629(67.1)$ \\
\hline Age (mean $\pm S D)$ & $36.86 \pm 14.549$ & $35.09 \pm 13.786$ & $38.61 \pm 9.202$ \\
\hline Age of onset & $33.98 \pm 14.344$ & $32.79 \pm 13.465$ & - \\
\hline$\leq 18$ years & 113(16.12) & $51(14.2)$ & - \\
\hline$\geq 19$ years & 588(83.88) & $309(85.8)$ & - \\
\hline Thyroid size & & & - \\
\hline Normal size (\%) & $22(3.1)$ & $12(3.3)$ & - \\
\hline Degree I (\%) & $127(18.1)$ & $59(16.4)$ & - \\
\hline Degree II (\%) & $425(60.7)$ & 253(70.3) & - \\
\hline Degree III (\%) & 127(18.1) & $36(10.0)$ & - \\
\hline Family history (\%) & $174(24.8)$ & $79(21.9)$ & \\
\hline Ophthalmopathy (\%) & 135(19.3) & $9(2.5)$ & - \\
\hline Thyroid antibodies & & & - \\
\hline TPOAb & 398(56.7) & $252(70.0)$ & - \\
\hline $\mathrm{TgAb}$ & $303(43.2)$ & $226(62.8)$ & - \\
\hline
\end{tabular}


GD, HT patients and controls. The clinical findings of AITD patients are also presented in Table 1.

\section{Association of rs3093023/rs3093024/rs6902119/rs9355610 polymorphisms with susceptibility to AITD}

The distribution of genotype frequencies of each SNP in both the patients and the controls were in Hardy-Weinberg equilibrium ( $p>0.05)$.

Differences in genotypic and allelic frequencies of SNPs between the patients and the controls were compared and are presented in Table 2. There were no significant differences in the allele or genotype frequencies of three SNPs of CCR6 (rs3093023, rs3093024, rs6902119) between AITD patients, GD patients, HT patients and controls. However, rs9355610 appeared to be associated with AITD susceptibility. The frequencies of rs9355610 genotypes in patients with GD (GG, 25.3\%; AG, 51.7\% and AA, 23.0\%) differed significantly from those in the controls (GG, 30.0\%; AG, 50.3\% and AA, 19.7\%) (p=0.017). We observed a significant increase in the frequency of the minor G allele of rs9355610 in the AITD and GD patients compared with that in healthy controls and seemed to have higher risks for AITD and GD (in AITD: 49.9\% vs.46.1\%; $\mathrm{p}=0.018, \mathrm{OR}=1.166,95 \% \mathrm{CI}=1.026-1.324$; in GD:51.2\% vs. $46.1 \% ; \mathrm{p}=0.005, \mathrm{OR}=1.225,95 \% \mathrm{CI}=1.063-1.412$ ).
However, we could not find significant differences in the genotype or allele frequencies of HT patients compared with those of healthy controls.

After gender stratification (shown in Table 3), the frequency of the minor $G$ allele of rs9355610 in both male and female GD patients was significantly higher than that in the healthy controls $(\mathrm{p}=0.036,0.048$; respectively); but the degree of risk for GD was higher in male group than in female group ( $\mathrm{OR}=1.308,95 \% \mathrm{CI}$ : 1.017-1.684 in males; $\mathrm{OR}=1.19,95 \% \mathrm{CI}=1.001-1.413$ in females); the genotype and the minor $\mathrm{G}$ allele distribution of rs9355610 did not reveal any significant association with $\mathrm{HT}$.

To examine the contribution of each SNP to susceptibility to AITD, conditional logistic regression analysis was conducted. As shown in Table 4, the association of rs9355610 remained significant after adjustment for rs6902119 SNP genotypes. Adjusted P values (P adjusted) for rs9355610 under the dominant model were 0.024 after adjustment for rs6902119. The results suggest that rs9355610 SNP is independently associated with GD.

\section{Haplotype analysis}

Linkage analysis of the four tested SNPs in the controls showed moderate to strong linkage disequilibrium (Table 5). To further identify whether haplotypes of those 4 SNPs

Table 2 Genotype and allele distribution of CCR 6- RNASET2 gene in AITDs patients, GD patients, HT patients, and controls

\begin{tabular}{|c|c|c|c|c|c|c|c|c|}
\hline \multirow[t]{2}{*}{ SNP } & \multicolumn{3}{|l|}{ Allele/ } & \multicolumn{2}{|l|}{$P_{a}$} & \multicolumn{2}{|l|}{$P_{b}$} & \multirow{2}{*}{$\begin{array}{l}P_{c} \\
(O R, 95 \% C l)\end{array}$} \\
\hline & Genotype & Controls & AITD & (OR, 95\% Cl) & GD & (OR, 95\% Cl) & HT & \\
\hline \multirow[t]{5}{*}{ rs3093023 } & GG & $329(36.9)$ & $341(33.4)$ & 0.252 & $224(33.3)$ & 0.242 & $117(33.4)$ & 0.428 \\
\hline & $A G$ & $423(47.5)$ & $507(49.6)$ & & $327(48.7)$ & & 180(51.4) & \\
\hline & $\mathrm{AA}$ & 139(15.6) & $174(17.0)$ & & $121(18.0)$ & & 53(15.2) & \\
\hline & A & $701(39.3)$ & $855(41.8)$ & 0.118 & $569(42.3)$ & 0.091 & $286(40.9)$ & 0.486 \\
\hline & G & $1081(60.7)$ & $1189(58.2)$ & & 775(57.7) & & $414(59.1)$ & \\
\hline \multirow[t]{5}{*}{ rs3093024 } & GG & $328(36.9)$ & $341(33.4)$ & 0.264 & $224(33.4)$ & 0.253 & 117(33.4) & 0.430 \\
\hline & $A G$ & $422(47.5)$ & $506(49.6)$ & & $326(48.6)$ & & $180(51.4)$ & \\
\hline & $\mathrm{AA}$ & 139(15.6) & $174(17.0)$ & & $121(18.0)$ & & $53(15.2)$ & \\
\hline & A & $700(39.4)$ & $854(41.8)$ & 0.124 & $568(42.3)$ & 0.096 & $286(40.9)$ & 0496 \\
\hline & G & 1078(60.6) & 1188(58.2) & & 774(57.7) & & $414(59.1)$ & \\
\hline \multirow[t]{5}{*}{ rs6902119 } & $\Pi$ & $344(38.7)$ & $373(36.5)$ & 0.468 & $233(34.7)$ & 0.183 & $140(40.0)$ & 0.888 \\
\hline & $C T$ & $420(47.2)$ & 487(47.7) & & $327(48.7)$ & & $160(45.7)$ & \\
\hline & CC & $126(14.1)$ & $162(15.8)$ & & 112(16.6) & & $50(14.3)$ & \\
\hline & C & 672(37.8) & $811(39.7)$ & 0.223 & $551(41.0)$ & 0.066 & $260(37.1)$ & 0.778 \\
\hline & $\mathrm{T}$ & $1108(62.2)$ & $1233(60.3)$ & & 793(59.0) & & $440(62.9)$ & \\
\hline \multirow[t]{5}{*}{ rs9355610 } & GG & 187(30.0) & $248(24.2)$ & 0.058 & $169(25.3)$ & 0.017 & $79(22.6)$ & 0.799 \\
\hline & $A G$ & $448(50.3)$ & $520(51.1)$ & & $345(51.7)$ & & 175(50.0) & \\
\hline & $\mathrm{AA}$ & 256(19.7) & $249(24.7)$ & & 153(23.0) & & $96(27.4)$ & \\
\hline & G & $822(46.1)$ & 1016(49.9) & 0.018 & $683(51.2)$ & 0.005 & $333(47.6)$ & 0.516 \\
\hline & A & $960(53.9)$ & $1018(50.1)$ & $1.166(1.026-1.324)$ & $651(48.8)$ & $1.225(1.063-1.412)$ & $367(52.4)$ & \\
\hline
\end{tabular}

$P_{a}$ value, AITD versus Controls; $P_{b}$ value, GD versus Controls; $P_{c}$ value, $H T$ versus Controls; $O R$, odd ratio; $95 \% C l, 95 \%$ confidence intervals. 
Table 3 Analysis of genotype and allele distribution of rs9355610 SNP in the GD patients and the controls after gender stratification

\begin{tabular}{|c|c|c|c|c|c|c|c|c|c|c|c|}
\hline \multirow[t]{3}{*}{ SNP } & \multirow{3}{*}{$\begin{array}{l}\text { Alleles/ } \\
\text { Genotypes }\end{array}$} & \multirow{2}{*}{\multicolumn{2}{|c|}{ Controls }} & \multirow{2}{*}{\multicolumn{2}{|c|}{ GD }} & \multirow{2}{*}{\multicolumn{2}{|c|}{ HT }} & \multirow{2}{*}{\multicolumn{2}{|c|}{$\begin{array}{l}P_{a} \\
\text { OR }(95 \% \mathrm{Cl})\end{array}$}} & \multirow{2}{*}{\multicolumn{2}{|c|}{$\begin{array}{l}P_{b} \\
\text { OR }(95 \% \mathrm{Cl})\end{array}$}} \\
\hline & & & & & & & & & & & \\
\hline & & $M(n=298)$ & $F(n=593)$ & $M(n=205)$ & $F(n=462)$ & $M(n=43)$ & $F(n=307)$ & $M$ & $\mathrm{~F}$ & $M$ & $\mathrm{~F}$ \\
\hline \multirow[t]{6}{*}{ rs9355610 } & GG & 63(21.1) & 124(20.9) & $56(27.3)$ & $113(24.5)$ & $8(18.6)$ & $71(23.1)$ & 0.110 & 0.124 & 0.741 & 0.675 \\
\hline & $A G$ & 148(49.7) & $300(50.6)$ & $104(50.7)$ & $241(52.2)$ & $20(46.5)$ & $155(50.5)$ & & & & \\
\hline & $\mathrm{AA}$ & $87(29.2)$ & $169(28.5)$ & $45(22.0)$ & 108(23.3) & $15(34.9)$ & $81(26.4)$ & & & & \\
\hline & \multirow[t]{2}{*}{ G } & 274(45.9) & $548(46.2)$ & $216(52.7)$ & $467(50.5)$ & $36(41.9)$ & 297(48.4) & 0.036 & 0.048 & 0.474 & 0.383 \\
\hline & & & & & & & & 1.308 & 1.19 & & \\
\hline & A & $322(54.1)$ & $638(53.8)$ & 194(47.3) & $457(49.5)$ & $50(58.1)$ & $317(51.6)$ & $1.017-1.684$ & $1.001-1.413$ & - & - \\
\hline
\end{tabular}

$M$, male; $F$, female; $P_{a}$ value, GD versus Controls; $P_{b}$ value, $H T$ versus Controls; OR, odd ratio; $95 \%$ Cl, $95 \%$ confidence intervals.

were correlated with AITD, we created an LD map and analyzed haplotype frequency differences between the AITD patients and the controls. Two detected LD blocks shown in Figure 1 are rs9355610-rs6902119, rs3093023rs3093024. Table 6 shows the frequency of haplotype AT in AITD and GD patients were significantly lower than that in their control groups $(p=0.016,0.003)$, the AT haplotype showed a protective effect on AITD and $\mathrm{GD}(\mathrm{OR}=0.856,95 \% \mathrm{CI}=0.754-0.972$; $\mathrm{OR}=0.806,95 \%$ $\mathrm{CI}=0.699-0.929)$; the frequency of haplotype GT in AITD and GD patients were significantly higher than that in their control groups $(\mathrm{p}=0.045,0.048$; respectively), indicating that GT was the risk haplotype to AITD and $\mathrm{GD}(\mathrm{OR}=1.245, \quad 95 \% \mathrm{CI}=1.005-1.541 ; \quad \mathrm{OR}=1.267$, $95 \% \mathrm{CI}=1.001-1.603)$. However, the haplotypes of block 2 were neither associated with GD nor with HT.

\section{Genotype and clinical phenotype correlations}

We also conducted a study on the effects of clinical parameters, including family history, age of onset $(\leq 18$ years or $\geq 19$ years), ophthalmopathy in GD patients, intractable GD or GD in remission and thyroid dysfunction in HT patients (Hypothyroidism or normal), on the association of the tested four SNPs with AITD. Unfortunately, the results demonstrated no detectable association of these parameters with these SNPs (data not shown).

\section{Discussion}

CCR6 encodes a receptor for macrophage inflammatory protein-3a (CCL20) that is expressed in unactivated memory B and T cells, Th17 cells and some dendritic cells and that plays a key role in B-cell differentiation and tissue-specific migration of dendritic and $\mathrm{T}$ cells during inflammatory and immunological responses [27]. A number of autoimmune diseases may share similar gene susceptibility and previous studies have reported significant associations between genetic polymorphisms of CCR6 and certain autoimmune diseases such as RA, Crohn's disease, SSc and vitiligo [19-23]. In this study, we investigated whether polymorphisms of CCR6 including

Table 4 Interaction analysis of gene-gene in AITD, GD and HT patients, by logistic regression*

\begin{tabular}{|c|c|c|c|c|c|c|c|c|c|}
\hline \multicolumn{10}{|c|}{ Codominant model } \\
\hline \multirow{2}{*}{$\begin{array}{l}\text { SNP } \\
\text { rs3093023 }\end{array}$} & \multicolumn{3}{|c|}{ rs3093024 } & \multicolumn{3}{|c|}{ rs6902119 } & \multicolumn{3}{|c|}{ rs9355610 } \\
\hline & 0.970 & 0.998 & 0.578 & 0.842 & 0.886 & 0.447 & 0.821 & 0.353 & 0.391 \\
\hline \multicolumn{10}{|l|}{ rs3093024 } \\
\hline rs6902119 & & & & & & & 0.941 & 0.492 & 0.441 \\
\hline \multicolumn{10}{|c|}{ Dominant model } \\
\hline \multicolumn{10}{|l|}{ SNP } \\
\hline rs3093023 & 0.392 & 0.721 & 0.106 & 1.0 & 1.0 & 0.09 & 0.738 & 0.874 & 0.157 \\
\hline rs3093024 & & & & & 1.0 & & & & \\
\hline rs6902119 & & & & & & & 0.370 & 0.024 & 0.181 \\
\hline \multicolumn{10}{|l|}{ Recessive } \\
\hline \multicolumn{10}{|l|}{ SNP } \\
\hline rs3093023 & 0.668 & 0.966 & 0.191 & 0.514 & 0.287 & 0.999 & 0.391 & 0.432 & 0.101 \\
\hline rs3093024 & & & & & & 0.999 & & & \\
\hline rs6902119 & & & & & & & 0.679 & 0.937 & 0.769 \\
\hline
\end{tabular}

*The data are presented as $P_{\text {adjusted }}$ values (AITD/GD/ HT) from a multiplicative interaction model. The regression models were adjusted for age and sex. 
Table 5 Linkage disequilibrium in controls

\begin{tabular}{llll}
\hline L1 & L2 & D' & r^2 \\
& & Controls & Controls \\
\hline rs9355610 & rs6902119 & 0.97 & 0.668 \\
rs9355610 & rs3093024 & 0.727 & 0.402 \\
rs9355610 & rs3093023 & 0.724 & 0.400 \\
rs6902119 & rs3093024 & 0.819 & 0.625 \\
rs6902119 & rs3093023 & 0.817 & 0.621 \\
rs3093024 & rs3093023 & 1.000 & 0.998 \\
\hline
\end{tabular}

rs3093023, rs3093024, rs6902119 and the RNASET2 tagSNP rs9355610 contributed to development of AITD in Chinese Han case-control cohorts. To our knowledge, the present study, which analyzed data from a large population of Chinese Han subjects, was the first to demonstrate an association between CCR6 polymorphisms and susceptibility to AITD in the Chinese Han population. Our results showed no association of three SNPs out of the four tested SNPs, i.e. rs3093023, rs3093024 and rs6902119 in the CCR6 gene, with AITD; however, the minor G allele of rs9355610 was significantly associated with susceptibility to GD.

With regard to the selection of the three SNPs of CCR6, the strategy was principally based on the papers

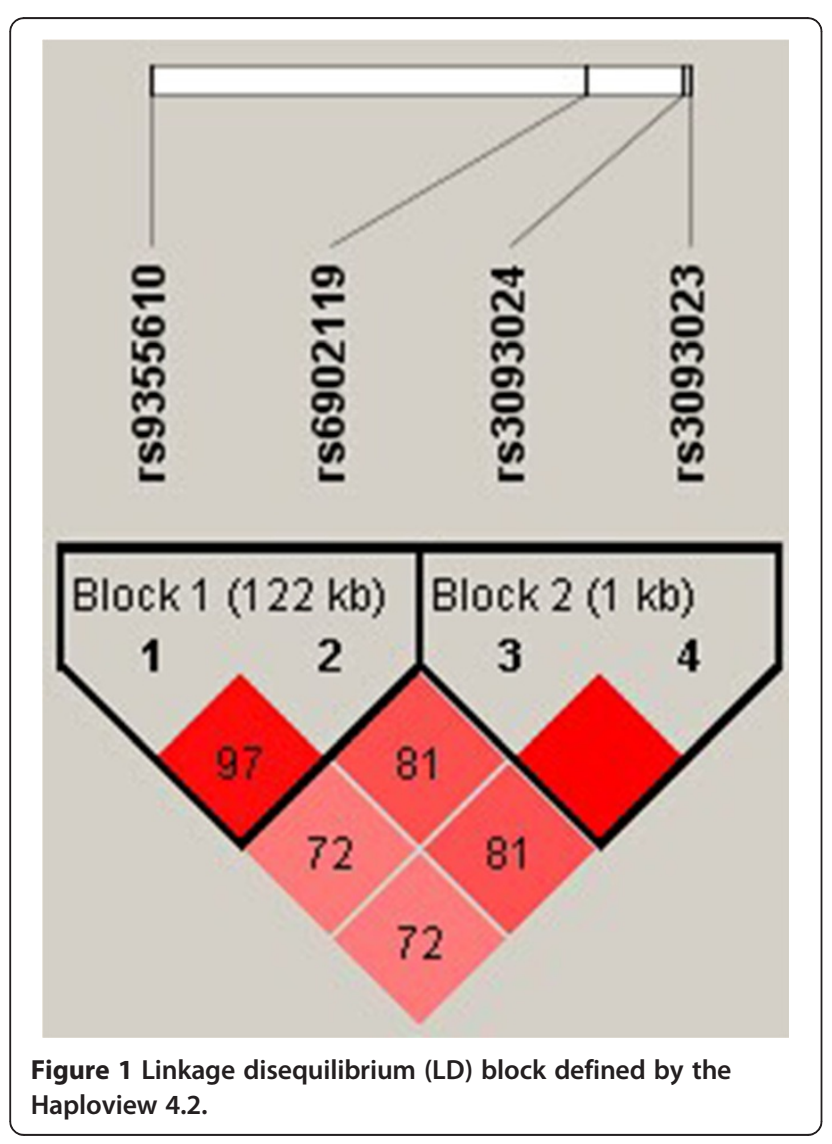

reported recently, which are mainly about CCR6 polymorphisms with RA and other autoimmune diseases using candidate gene approaches and genome-wide association studies (GWAS) [19,20]. Recent GWAS have identified SNPs in the 6q27 region associated with RA (rs3093024 and rs3093023 near CCR6) [19,20] and vitiligo (rs6902119 near CCR6) [28]. Rs3093023/rs3093024 have been proved to be as the new risk locis for RA in different ethnic groups, including Japanese [20], Singaporeans [29] and Europeans [19]; rs6902119 has been identified as risk loci for vitiligo in Japanese [28]. Unexpectedly, researchers did not detect any significant associations in the Chinese Han population between rs3093023/rs3093024/rs6902119 and Vogt-Koyanagi-Harada Syndrome, a well known autoimmune disease involving the eye, the neurologic/auditory and integument organs [30]. In the association study on CCR6 SNPs (rs3093023/rs3093024/rs6902119) with susceptibility to Behcet's disease, no association was found in the Chinese Han population, either [31]. To our knowledge, there has been no association study on CCR6 SNPs (rs3093023/rs3093024/rs6902119) with AITD in the Chinese population. Our present study showed no significant associations between three tested SNPs of CCR6 and AITD patients in the Chinese population ( $\mathrm{p}>0.05)$, which was consistent with that of the above association study reported in Vogt-Koyanagi-Harada Syndrome and Behcet's disease in the Chinese han population. The absence of an association in our study is contrary to the results reported in other autoimmune diseases including RA, SSc and vitiligo in European and Asian populations [19-23,28,29]. This might be explained by the fact that the etiology and pathogenesis of AITD is different from that of the other autoimmune diseases. Another possibility could be that Chinese Han people have a genetic background different from that of other ethnic populations.

Recently Chu et al. [24] has conducted a two-stage GWAS within the Chinese Han population and identified rs9355610 as the novel GD susceptibility locus within 6q27 chromosomal near CCR6 gene. The rs9355610 is located in a block spanning the 5' exons of RNASET2 and the intergenic region in the Chinese population. It is found that the risk allele $G$ of rs9355610 is significantly associated with reduced mRNA level of RNASET2 only in $\mathrm{CD}^{+}$and $\mathrm{CD}^{+} \mathrm{T}$ cells isolated from 106 healthy Chinese $\left(\mathrm{p}=6.42 \times 10^{-11}\right.$ and $\mathrm{p}=2.00 \times 10^{-7}$, respectively $)$ [24]. RNASET2 is the only RNase T2 family member in humans; the study showed that omega-1, an RNase T2 family member secreted from the eggs of Schistosoma mansoni, plays a role in priming human dendritic cells for Th2 polarization of $\mathrm{CD}^{+}{ }^{+} \mathrm{T}$ cells [32], indicating that human RNASET2 might be involved in immune response and therefore underlie the pathogenesis of GD.

A study carried out in the Polish Caucasian population with 560 GD patients and 1475 unrelated healthy 
Table 6 Haplotype analysis of AITDs patients and controls

\begin{tabular}{|c|c|c|c|c|c|c|c|c|c|c|}
\hline Haplotype & $\begin{array}{l}\text { Controls } \\
\text { (Frequency) }\end{array}$ & AITD & $\mathbf{P}$ & OR $(95 \% \mathrm{Cl})$ & GD (Frequency) & $\mathbf{P}$ & OR $(95 \% \mathrm{Cl})$ & HT (Frequency) & $P$ & OR $(95 \% \mathrm{Cl})$ \\
\hline \multicolumn{11}{|l|}{ Block 1} \\
\hline \multirow[t]{2}{*}{ AT } & 952(53.3) & 1010(49.4) & 0.016 & 0.856 & 644(47.9) & 0.003 & $0.806(0.699-0.929)$ & $366(52.2)$ & 0.626 & - \\
\hline & & & & $0.754-0.972$ & & & & & & \\
\hline GC & $663(37.2)$ & 795(38.9) & 0.265 & - & $536(39.9)$ & 0.116 & - & 259(37.0) & 0.955 & - \\
\hline \multirow[t]{2}{*}{ GT } & $160(8.9)$ & 223(11.0) & 0.045 & 1.245 & 149(11.1) & 0.048 & $1.267(1.001-1.603)$ & 74(10.6) & 0.215 & - \\
\hline & & & & $1.005-1.541$ & & & & & & \\
\hline \multicolumn{11}{|l|}{ Block 2} \\
\hline GG & $1079(60.5)$ & $1188(58.2)$ & 0.136 & & 774(57.7) & 0.105 & - & $414(59.1)$ & 0.519 & - \\
\hline AA & $703(39.5)$ & $854(41.8)$ & 0.136 & & $568(42.3)$ & 0.105 & - & 286(40.9) & 0.519 & - \\
\hline
\end{tabular}

AITDs, autoimmune thyroid diseases; GD, Graves' disease; HT, Hashimoto's thyroiditis; OR, odds ratio; Cl, confidence interval.

controls using TaqMan assay showed no significant association of allelic frequency distribution of rs 9355610 between GD and controls $(p=0.082)$ [33]. In our present study, we found that the $G$ allele of rs9355610 significantly increased the risk of GD ( $\mathrm{p}=0.005, \mathrm{OR}=1.225)$, but did not associate with HT. This result is consistent with that of the report on 457 Japanese AITD patients and 222 matched healthy controls which found that the SNPs rs9355610 was significantly associated with GD ( $p=0.047$ ), the $G$ allele of rs9355610 was higher in GD patients than in controls $(\mathrm{p}=0.0055, \mathrm{OR}=1.42)$, and the GG genotype was also significantly increased in GD patients compared with that in the controls $(p=0.026$, $\mathrm{OR}=1.63$ ). All these evidently indicated that the TT genotype could increase susceptibility to GD; nevertheless, there was no association between rs9355610 and HT [34].

Because analysis of haplotype provides the genetic information of multiple SNPs, this is a powerful method for the identification of genes contributing to complex diseases. In our study, the associated haplotype was in the same LD block. The rate of AT haplotype was lower in GD, suggesting a protective effect on GD, while the rate of the haplotype GT was higher, indicating a significant risk factor for GT. This consistency with allele analysis strongly confirms that $\mathrm{G}$ allele of rs 9355610 was a predisposing factor for AITD.

It is worthwhile to point out that several limitations exist in our study. Although

The association with the RNASET2 gene suggests that $\mathrm{G}$ allele affect expression of RNASET2 gene in CD4+ and $\mathrm{CD} 8^{+} \mathrm{T}$ cell, we did not perform biological function tests in control carriers of the various phenotypes. Because of limited SNPs included in our study, future study using the high-throughput analytic methods available (i.e., gene sequencing) may help clarify our findings and provide further insight into the role of CCR6 in AITD.

\section{Conclusions}

This study indicates that the G allele of the RNASET2 tag SNP rs9355610, but not rs3093023, rs3093024 or rs6902119 in the CCR6 gene, is associated with susceptibility to GD in the Chinese Han population.

\section{Abbreviations}

CCR6: CC chemokine receptor 6; AITDs: Autoimmune thyroid diseases; GD: Graves' disease; HT: Hashimoto's thyroiditis; SNPs: Single nucleotides polymorphisms; PCR: Polymerase chain reaction; LDR: Ligase detection reaction; CTLA-4: Cytotoxic T lymphocyte-associated factor 4; PTPN22: Protein tyrosine phosphatase-22; TSHR: Thyroid stimulating hormone receptor; TG: Thyroglobulin; RA: Rheumatoid arthritis; CD: Crohn's disease; SSc: Systemic sclerosis; GWAS: Genome-wide association study; TRAb: Thyroid stimulating hormone receptor antibody; TPO-Ab: Anti-thyroid peroxidase antibody; Tg-Ab: Anti-thyroglobulin antibody; FNAB: Fine needle aspiration biopsies.

\section{Competing interests}

The authors declare that they have no competing interests.

\section{Authors' contributions}

X-JC and X-HG supervised the study, carried out the genotyping. SM, QQ Y-FJ and $\mathrm{H}-\mathrm{YZ}$ helped collection specimens. NY conducted the data analysis and wrote the manuscript. JZ designed the study and coordinated the research team. All authors had read and approved the final manuscript.

\section{Acknowledgments}

This project was supported by grants from the National Natural Science Foundation of China (81270871), and the Key Disciplines Development of Shanghai Jinshan District (No. 2012-23).

We would like to thank all the patients and the controls for their participation in our study. We thank all members and all participant organizations of the research group for their contributions to the investigation.

\section{Author details}

${ }^{1}$ Department of Endocrinology, The First Affiliated Hospital of Wenzhou Medical University, No.2 Fuxuexiang Road, Ouhai District, 325000 Wenzhou, China. 'Department of Endocrinology, Jinshan Hospital of Fudan University, No.1508 Longhang Road, Jinshan District, 201508 Shanghai, China.

Received: 6 October 2014 Accepted: 29 January 2015

Published online: 26 February 2015

\section{References}

1. Tomer $Y$, Huber $A$. The etiology of autoimmune thyroid disease: a story of genes and environment. J Autoimmun. 2009;32:231-9.

2. Menconi F, Oppenheim YL, Tomer Y. Diagnostic Criteria in Autoimmune Diseases. Part V: Graves Disease; 2008. p. 231-5. 
3. Tomer $Y$, Davies TF. Searching for the autoimmune thyroid disease susceptibility genes: from gene mapping to gene function. Endocr Rev. 2003;24(5):694-717.

4. Hodge SE, Ban Y, Strug LJ, Greenberg DA, Davies TF, Concepcion ES, et al. Possible interaction between HLA-DR $\beta 1$ and thyroglobulin variants in Graves' disease. Thyroid. 2006;16(4):351-5.

5. Jacobson EM, Tomer Y. The CD40, CTLA-4, thyroglobulin, TSH receptor, and PTPN22 gene quintet and its contribution to thyroid autoimmunity: Back to the future. J Autoimmun. 2007;28(2-3):85-98.

6. Yang J, Qin Q, Yan N, Zhu YF, Li C, Yang XJ, et al. CD40 C/T -1 and CTLA-4 $\mathrm{A} / \mathrm{G}_{49}$ SNPs are associated with autoimmune thyroid diseases in the Chinese population. Endocrine. 2012;41(1):111-5.

7. Tomer Y, Concepcion E, Greenberg DA. A C/T single-nucleotide polymorphism in the region of the CD40 gene is associated with Graves' disease. Thyroid. 2002;12(12):1129-35.

8. Liu L, Wu HQ, Wang Q, Zhu YF, Zhang W, Guan L, et al. Association between thyroid stimulating hormone receptor gene intron polymorphisms and autoimmune thyroid disease in a Chinese Han population. Endocr J. 2012;59(8):717-23.

9. Maierhaba M, Zhang JA, Yu ZY, Wang Y, Xiao WX, Quan Y, et al. Association of the thyroglobulin gene polymorphism with autoimmune thyroid disease in Chinese population. Endocrine. 2008;33(3):294-9.

10. Yan N, Yu YL, Yang J, Qin Q, Zhu YF, Wang X, et al. Association of interleukin-17A and -17F gene single-nucleotide polymorphisms with autoimmune thyroid diseases. Autoimmunity. 2012:45(7):533-9.

11. Zhang J, Xiao WX, Zhu YF, Muhali FS, Xiao L, Jiang WJ, et al. Polymorphisms of interleukin-21 and interleukin-21-receptor genes confer risk for autoimmune thyroid diseases. BMC Endocr Disord. 2013;29:13-26.

12. Kitamura K, Farber JM, Kelsall BL. CCR6 marks regulatory T cells as a colon-tropic, IL-10-producing phenotype. J Immunol. 2010;185(6):3295-304.

13. Schutyser E, Struyf S, Van Damme J. The CC chemokine CCL20 and its receptor CCR6. Cytokine Growth Factor Rev. 2003;14(5):409-26.

14. Liao F, Shirakawa AK, Foley JF, Rabin RL, Farber JM. Human B cells become highly responsive to macrophage-inflammatory protein-3 alpha/CC chemokine ligand-20 after cellular activation without changes in CCR6 expression or ligand binding. J Immunol. 2002;168(10):4871-80.

15. Lee AY, Körner H. CCR6 and CCL20: emerging players in the pathogenesis of rheumatoid arthritis. Immunol Cell Biol. 2014;92(4):354-8.

16. Lee AY, Eri R, Lyons AB, Grimm MC, Korner H. CC chemokine ligand 20 and its cognate receptor CCR6 in mucosal T cell immunology and inflammatory bowel disease: odd couple or axis of evil? Front Immunol. 2013;4:194.

17. Figueroa-Vega N, Alfonso-Pérez M, Benedicto I, Sánchez-Madrid F, GonzálezAmaro R, Marazuela M. Increased circulating pro-inflammatory cytokines and Th17 lymphocytes in Hashimoto's thyroiditis. J Clin Endocrinol Metab. 2010;95(2):953-62

18. Qin Q, Liu P, Liu L, Wang R, Yan N, Yang J, et al. The increased but nonpredominant expression of Th17- and Th1-specific cytokines in Hashimoto's thyroiditis but not in Graves' disease. Braz J Med Biol Res. 2012;45(12):1202-8.

19. Stahl EA, Raychaudhuri S, Remmers EF, Xie G, Eyre S, Thomson BP, et al. Genome-wide association study meta-analysis identifies seven new rheumatoid arthritis risk loci. Nat Genet. 2010;42(6):508-14.

20. Kochi Y, Okada Y, Suzuki A, Ikari K, Terao C, Takahashi A, et al. A regulatory variant in CCR6 is associated with rheumatoid arthritis susceptibility. Nat Genet. 2010;42(6):515-9.

21. Barrett JC, Hansoul S, Nicolae DL, Cho JH, Duerr RH, Rioux JD, et al. Genome-wide association defines more than 30 distinct susceptibility loci for Crohn's disease. Nat Genet. 2008:40(8):955-62.

22. Koumakis E, Bouaziz M, Dieudé P, Ruiz B, Riemekasten G, Airo P, et al. A regulatory variant in CCR6 is associated with susceptibility to antitopoisomerasepositive systemic sclerosis. Arthritis Rheum. 2013;65(12):3202-8.

23. Quan C, Ren YQ, Xiang LH, Sun LD, Xu AE, Gao XH, et al. Genome-wide association study for vitiligo identifies susceptibility loci at 6q27 and the MHC. Nat Genet. 2010;42(7):614-8.

24. Chu X, Pan CM, Zhao SX, Liang J, Gao GQ, Zhang XM, et al. genome-wide association study identifies two new risk loci for Graves' disease. Nat Genet. 2011:43(9):897-901.

25. Yan N, Meng S, Zhou J, Xu J, Muhali FS, Jiang W, et al. Association between STAT4 Gene Polymorphisms and Autoimmune Thyroid Diseases in a Chinese Population. Int J Mol Sci. 2014;15(7):12280-93.

26. Dupont WD, Plummer Jr WD. Power and sample size calculations for studies involving linear regression. Control Clin Trials. 1998;19(6):589-601.
27. Salazar-Gonzalez RM, Niess JH, Zammit DJ, Ravindran R, Srinivasan A, Maxwell $J R$, et al. CCR6-mediated dendritic cell activation of pathogen-specific $T$ cells in Peyer's patches. Immunity. 2006;24(5):623-32.

28. Jin Y, Birlea SA, Fain PR, Mailloux CM, Riccardi SL, Gowan K, et al. Common variants in FOXP1 are associated with generalized vitiligo. Nat Genet. 2010;42(7):576-8.

29. Teng E, Leong KP, Li HH, Thong B, Koh ET, Loi PL, et al. Analysis of a genome-wide association study-linked locus (CCR6) in asian rheumatoid arthritis. DNA Cell Biol. 2012;31(4):607-10.

30. Yi X, Du L, Hou S, Li F, Chen Y, Kijlstra A, et al. FGFR1OP tag SNP but not CCR6 polymorphisms are associated with vogt-koyanagi-harada syndrome in Chinese Han. PLoS One. 2013;8(7):e69358.

31. Yi X, Yang P, Du L, Jiang Z, Li F. There is no association of CCR6 polymorphisms with susceptibility toBehcet's disease in two Chinese Han populations. Br J Ophthalmol. 2011;95(11):1603-6.

32. Steinfelder S, Andersen JF, Cannons JL, Feng CG, Joshi M, Dwyer D, et al. The major component in schistosome eggs responsible for conditioning dendritic cells for Th2 polarization is a T2 ribonuclease (omega-1). J Exp Med. 2009;206(8):1681-90.

33. Szymański K, Bednarczuk T, Krajewski P, Płoski R. The replication of the association of the rs6832151 within chromosomal band 4p14 with Graves' disease in a Polish Caucasian population. Tissue Antigens. 2012;79(5):380-3.

34. Ban Y, Tozaki T, Taniyama M. The replication of the association of the rs9355610 within 6p27 with Graves' disease. Autoimmunity. 2013:46(6):395-8.

\section{Submit your next manuscript to BioMed Central and take full advantage of:}

- Convenient online submission

- Thorough peer review

- No space constraints or color figure charges

- Immediate publication on acceptance

- Inclusion in PubMed, CAS, Scopus and Google Scholar

- Research which is freely available for redistribution 